\title{
Vicarious Group Trauma among British Jews
}

\author{
Christina Fuhr ${ }^{1}$
}

Published online: 12 July 2016

(C) The Author(s) 2016. This article is published with open access at Springerlink.com

\begin{abstract}
Given that literature on the intra- and inter-generational transmission of traumas is mainly based on secondary literature and focuses on the transmission of trauma memory in terms of the historical knowledge of group trauma, this article develops the theory of vicarious group trauma and tests this theory by exploring vicarious traumatization in the everyday lives of Jews in Britain through the methods of observation and in-depth interviewing. Vicarious group trauma is defined as a life or safety-threatening event or abuse that happened to some members of a social group but is felt by other members as their own experience because of their personal affiliation with the group. The article finds that the vicarious sensation of traumatic group experiences can create anxiety, elicit perceptions of threat and, by extension, hypervigilance among Jews. The findings demonstrate that group traumas of the past interpenetrate and interweave with members' current lives and in this way can also become constitutive of their group identity. An institutional focus on threats to Jews can inform the construction and reinforcement of traumatization symptoms and accordingly vicarious group trauma. This article suggests an association between the level of involvement of group members in the collective's social structure and the prominence of vicarious group trauma among them.
\end{abstract}

Keywords Britain · Emotions · Holocaust $\cdot$ Identity $\cdot$ Jews $\cdot$ Memory Perception · Trauma Traumatization

There is a focus in sociology on the intra- and inter-generational transmission of traumas (e.g. Alexander et al. 2004; Eyerman et al. 2011). Most of this research is based on secondary literature and focuses on the transmission of trauma memory in terms of the historical knowledge of group trauma and its impact on the identity of the collective. In this article, I extend this work by studying the symptoms of traumatization among members who have not gone through the group trauma themselves. I argue that in this way transmitted traumas can become constitutive of members' group identity. To do so, I develop the theory of vicarious

Christina Fuhr

christina.fuhr@gmail.com

1 Woolf Institute, 12-14 Grange Road, Cambridge, UK 
group trauma. Vicarious group trauma is defined in this article as a life- or safety-threatening event or abuse that happened to some members of a social group but is felt by other members as their own experience because of their personal affiliation with the group. When many members of a group feel as if they experienced the group trauma themselves by having symptoms of traumatization or can be attested to have those symptoms, we speak of vicarious group trauma.

This article will test the theory by exploring vicarious traumatization in the everyday lives of Jews in Britain through the methods of observation and in-depth interviewing. Therefore, the article presents a description of the actual traumas that are communicated to and remembered by different kinds of Jewish people. It finds that secular participants - meaning synagogue (affiliated) members who are less or not at all engaged with Judaism as a religion, culture and community as well as synagogue (unaffiliated) members - tend to remember only the Holocaust. This is proposed to be related to the communication of the event through mainstream culture and education in addition to, if applicable, personal family stories. Devout affiliated members have a propensity to also remember earlier Jewish traumas such as the enslavement in Egypt and their exodus over a hundred years later. This is suggested to be related to the observation of holy days associated with those traumas in Jewish schools, homes and synagogues, on top of, if applicable, family stories.

Due to a personal identification with the trauma on an emotional level because of a shared group membership, members of the community can feel the traumatic experience as their own. The article then illustrates that the vicarious sensation of such traumatic group experiences can create anxiety, elicit perceptions of threat and, by extension, hypervigilance among Jews. Vicarious traumatization symptoms, particularly perceptions of threat and hypersensitivity, are prominent among community-involved unaffiliated and particularly among engaged affiliated members. The narratives below demonstrate that group traumas of the past interpenetrate and interweave with members' current lives and in this way can also become constitutive of their group identity.

Lastly, the article shows how an institutional focus on past and present threats to Jews can inform the construction of traumatization symptoms and accordingly vicarious group trauma. Considering that vicarious trauma is present to a greater extent among community-involved Jews, especially affiliated engaged ones, this type of member is also found to be more exposed to constant and multiple traumatization mediators - communicated indicators of current threat and past trauma - through communal structures because of their physical and social proximity to them. Thus, this article indicates an association between the level of involvement of group members in their collective's social structure and the prominence of vicarious trauma among them. Overall, the article illustrates how a group's institutions, including the family, can create a siege mentality among members by emphasizing threats to them.

The Jewish community presents an obvious and interesting case study as research has shown that trauma memory and particularly the Holocaust is prominent among members of this group and an essential part of their identity (e.g. Alexander 2004a; Freud 1932; Zerubavel 1996; Lazar et al. 2008; Kugelmass 1996); however, there is a lack of such research with regards to British Jews, highlighting the necessity for this present study. The evidence provided for the Jewish group is regarded as symptomatic of the impact conflict can have on any minority group. For example, the recent war in Syria can be expected to affect many Syrians around the world as much as the 1994 genocide for the Rwandan diaspora. Equally disturbing can be traumas that are less recent, such as the times of slavery for the AfroAmerican community in the United States or the partition of Punjab in 1947 for Sikhs. All of 
those traumas have been communicated through social and, thus, institutional mechanisms such as museums, civic commemorations and the media. Hence, the perspectives of Jews in this study will provide a significant example of the real and long-term effects transmitted group traumas can have on their members and the identification with their collective as well as the powerful role institutions play in creating and maintaining a vicarious trauma experience.

\section{Vicarious Group Trauma}

There has been a focus in sociological research on the exploration of trauma transmission. Most of such research, however, uses secondary literature to examine how trauma memory in the form of historical facts and experiences of trauma is transmitted to members who have not personally experienced the trauma, and can become part of their association with the group and in this way binds them together rather than disconnecting them (Assmann 2006; Eyerman 2011; Eyerman et al. 2011). Zerubavel (1996), for instance, theorizes that "being social presupposes the ability to experience events that happened to groups and communities to which we belong long before we joined them as if they were part of our own past." Alexander et al. $(2004,1)$ similarly assert that "a cultural trauma occurs when members of a collectivity feel they have been subjected to a horrendous event that leaves indelible marks upon their group consciousness, marking their memories forever." To construct a cultural trauma, the memory of the traumatic event needs to be part of the cultural and public discourse and represented as being destructive and threatening to the existence of the group, its culture, and members' personal identity. Contributors to the book apply the model in a series of case studies, including the Holocaust and slavery in the United States.

There is also a small set of qualitative and quantitative literature that analyses the Holocaust as a cultural trauma specifically in the second and third-generation offspring of Holocaust survivors (Scharf 2007; Kellerman 2001; Litvak-Hirsch and Bar-On 2006), also in comparison to the offspring of non-survivors (Lazar et al. 2004). The survey findings by Lazar et al. (2008) suggest that there are sociocultural mechanisms at work in Israel - such as Holocaust education and the country's perceived role as providing security for Jewish people - that influence the third-generation offspring of both Holocaust survivors and non-survivors to perceive the Holocaust as a cultural trauma. ${ }^{1}$

Indeed, there are various social mechanisms that can be responsible for the transmission of trauma memory. Research by scholars such as Alexander et al. (2004) and Eyerman (2011) demonstrates the importance of carrier groups (e.g. the mass media) in imparting trauma to members who have not experienced it directly. In this way the trauma becomes part of the group identity and can therefore also change a group's "future identity in fundamental and irrevocable ways" (Alexander 2004b). Carrier groups "articulate the significance of and represent the trauma for the collective...making it available for communication and shared understanding... They help transform emotional responses into words and images that can be dispersed and remembered" (Eyerman 2011). Hirsch (2008), for instance, examines how the trauma of the Holocaust is transmitted through the arts, specifically photography, to the second generation. Hirsch $(2008,103)$ developed the concept of postmemory to describe "the relationship of the second generation to powerful, often traumatic, experiences that preceded their

\footnotetext{
${ }^{1}$ These recent quantitative findings resonate with analyses from earlier studies based on secondary literature such as Ben-Amos and Bet-El's (1999) research about collective trauma remembrance in the form of memorial ceremonies in Israeli schools and its impact on Jewish national identity.
} 
births but that were nevertheless transmitted to them so deeply as to seem to constitute memories in their own right."

Landsberg $(1997,2004)$ emphasizes the importance of mass cultural technologies — producing a unique transmission of images and narratives about the past - in making it possible to take on memories of events through which people did not live. The sensuous engagement that experiential museums or technological developments (e.g. the mass dissemination of film) provide enables secondary memory formation. Landsberg $(1997,66)$ referred to these memories as prosthetic memories, arguing that while "the traumatic experiences are not originally based, they are nevertheless experiences with one's own body... and as such, become part of one's personal archive of experience, informing not only one's subjectivity, but one's relationship to the present and future tenses."

While the sociological literature has focused on the transmission of trauma memory on the group level, the psychiatric and psychology literature has concentrated on exploring trauma transmission at the individual level, understanding the term trauma simply "as a wound inflicted not upon the body but upon the mind" (Caruth 1996; Eyerman 2011). Accordingly, trauma is an emotional experience of the historical knowledge of trauma that is stored in a person's longterm memory and is so strong as to bypass rationality and affect the person's cognition and emotions. Such research has looked at how the trauma can be transmitted to another person. Studies such as by McCann and Pearlman (1990) found that trauma may be experienced by people who come into contact with trauma victims over a prolonged period of time, e.g. family members or therapists, as they are able to suffer signs and symptoms of traumatization similar to those of the victim. They termed the process vicarious traumatization. The outcome has also been labelled secondary trauma by others such as Figley (1983). For example, there is evidence that children of Holocaust survivors (Danieli 1985; Prince 2009) and Vietnam combat veterans (Rosenheck and Nathan 1998) can experience social and psychological difficulties that are symptomatic of posttraumatic stress disorder. The psychiatric and psychology literature demonstrates on the individual level how the actual trauma can be transmitted to another person who has not lived through the traumatic experience themselves by analyzing the symptoms of traumatization that they display. Nevertheless, there is a gap in the sociological literature exploring empirically vicarious traumatization in everyday life on the group level.

As a response, I outline a theory of vicarious group trauma. Vicarious group trauma is defined in this article as a life or safety-threatening event or abuse that happened to some members of a social group but is felt by other members as their own experience as they personally identify with the trauma on an emotional level because of their shared group membership. As mentioned above, sociological and psychological literature already suggests it is the resulting emotional experience of the life- or safety-threatening event or abuse, despite not having suffered the trauma themselves, which creates trauma memory.

For example, Landsberg (2009) argues that people who have not lived through trauma can still adopt its memory through the personal emotional experience of empathy in response to the communicated trauma knowledge. I extend this theory by arguing that through individuals' personal association with the trauma as a member of the group, the historical fact of trauma or the communicated knowledge of the life or safety-threatening event or abuse can become an emotional trauma experience - an emotional wound - for individuals, who have not directly experienced it. The historical knowledge is tagged with powerful emotions so that it becomes an experience for them, and in this way, the transmitted trauma can impact on their emotions and perceptions of the world. When many members can be attested, or they themselves attest, to have this emotional experience associated with the trauma, the personal visceral trauma becomes a shared trauma; in other words vicarious group trauma. 
The actual trauma memory can differ between members who have gone through the trauma themselves and those who have not, but both types of members may, nonetheless, have an emotional experience of the remembered trauma, which can be felt in similar ways. A personal association with the transmitted trauma knowledge on the emotional level as a result of group membership can be a common phenomenon among members because they are able to feel that the trauma could have happened to them as well. This emotional immediacy makes the memory powerful enough to elicit strong emotions and perceptions.

Group membership is crucial in the construction of vicarious group trauma. For example, a non-Jewish person visiting the Holocaust Museum in Washington DC may start feeling a connection with the trauma and adopt the prosthetic memory as described by Landsberg (2004). It may, however, be unlikely that the memory will be strong enough to result in secondary traumatization - by having an emotional experience that allows them to feel as if they themselves have been subject to the traumatic experience and results in symptoms of traumatization - if they have no direct ethno-religious association with the group, or, as noted above, if they have not spent time with a survivor of that trauma. The historical fact of trauma, which may also involve an emotional response providing the memory with strength, can be taken on by anyone without any direct personal relation to the traumatic event, or the person(s) it happened to. However, the actual traumatization with its symptoms as a result of the communicated trauma knowledge and accordingly the viscerally felt traumatic experience may not be created.

It follows, then, that vicarious group trauma can act within and across many generations and become part of members' identity. The theory distinguishes itself clearly from other theories on trauma transmission, such as Hirsch's (2008) concept of postmemory, as the focus of its conceptualization rests on the transmission of the actual trauma in terms of an emotional traumatic experience rather than the historical knowledge of trauma.

Reviewing the literature, we find that there is a gap in sociological research studying secondary group traumatization on the micro-level. Ethnographic research is needed to study not only how vicarious group traumatization manifests itself among individual members, impacting their identification with the group, but also how the traumatization is informed and sustained.

While there have been interesting analyses of how past Jewish traumas can be a part of group identity and can be effective in sustaining that identity (e.g. Freud 1932), there is little published research about group trauma among British Jews and its effect. Cooke (2000) examines how debates over the perceived appropriateness of Holocaust memorial sites in London structure various discourses concerning Anglo-Jewish identity. Another study, by Berman (2004), looks at Holocaust commemorations in London and discusses the relationship between the commemoration and unity formation, suggesting that associated rituals and collective mourning help to bind this community together. While both are helpful in shedding light on the importance of trauma remembrance in the creation and perpetuation of Jewish identity in Britain, neither of these or other studies engaged in primary research methods such as ethnography. This work uses in-depth interviewing and observations to contribute to the existing research by exploring vicarious traumatization among members of the British Jewish community.

\section{Methods}

This research is part of a larger ethnographic study on Jewish identity construction and perpetuation in contemporary Britain. The data are derived from observations of, and semistructured interviews with, British Jews. The interviews first asked very open questions about 
interviewees' sense of Jewishness. This allowed me to follow up on what the respondents regarded as important in their identification with Judaism. The rest of the questions dealt with their upbringing, the impact being Jewish had on their current lives, the community, Jewish language, their relations to other Jews, as well as their views on particular topics, namely Christmas, partnership, Israel, and anti-Semitism past and present. Interview findings in this article are not based on answers to a specific question about the Holocaust. While I asked "Do you think that the Holocaust has an impact on your life?" I only posed this question towards the end of the interview as part of a wider set of questions dealing with anti-Semitism. By then vicarious group trauma and symptoms of traumatization had often already come up in implicit and explicit ways.

The data were collected between October 2008 and October 2009. My study focuses on Modern Orthodox as well as Progressive (Liberal and Reform) Jews and Jews without synagogue affiliation. These three groups are the largest ones in Britain. Among the affiliated Jewish groups, the Modern Orthodox is the biggest group (55\%), followed by the Progressive $(19.4 \% \text { Reform, } 8.7 \% \text { Liberal })^{2}$ and then the Ultra-Orthodox (11\%), Sephardim (3.5\%) and Masorti $(2.7 \%)^{3}$ (Graham and Vulkan 2010). The unaffiliated population size ranges between 25 and $50 \%$ according to statistics (Schmool and Cohen 1998; Graham and Vulkan 2010) and predictions made by researchers from the Institute of Jewish Policy Research in London.

Although most of the in-depth interviews were conducted with Jews from these three groups, I also interviewed a few Masorti and Ultra-Orthodox members in order to get a wellrounded overview of Jewish identification. Of the 105 interviewees I conducted, four interviews were with Ultra-Orthodox members, 33 with Modern Orthodox Jews, four with Masorti, 19 with Progressive and 45 with unaffiliated Jews. All respondents were above 18. The majority of interviewees were below 50 . The inclusion of a substantial number of interviewees below 50 allowed me to look carefully at whether younger Jews express significantly different answers to my interview questions. I expected to observe differences between younger and older Jews with respect to experiences of traumatization in response to transmitted trauma memory, given that the Holocaust may be a more distant memory for younger Jews. Such differences could not be observed.

The interview sample has an approximately equal spread of gender (56\% male, $44 \%$ female) and different levels of engagement with Judaism. Engagement with Judaism is measured in terms of the interviewees' level of ethno-religious practice (e.g. observance of the major holy days and dietary restrictions) and their involvement with the community, including the culture. Regarding the former, I looked at the respondents' involvement with other Jewish people (e.g. friends and acquaintances) and in community institutions. In consideration of the latter, I looked at their engagement in "Jewish activities," such as reading about Jewish related issues or books by Jewish authors. The overall project was primarily interested in finding out how Jewish identity is sustained and perpetuated. Thus, while the study also included unaffiliated Jews who would not mention that they were Jewish unless they were asked and were completely removed from the Jewish community, religion and culture, its focus was on Jews who maintain an affiliation to Judaism. The sample does not reflect a wide demographic spread in terms of social class. The majority of the respondents

\footnotetext{
${ }^{2}$ Liberal Judaism in Britain is similar to the Reform Judaism in North America. The North American Reform movement and British Liberal Judaisms are located on the more radical end of the non-orthodox movements of Judaism, followed by the British Reform movement.

${ }^{3}$ Masorti Judaism is synonymous to Conservative Judaism in the United States and Canada.
} 
identified themselves as middle class (84\%). The statistic of middle-class respondents does, however, resonate with the results of the 2011 Census, suggesting that a majority of Jews in Britain are middle class (Graham et al. 2007). Most of the interviewees were from London, as over half of Britain's enumerated Jews $(171,960$ of 269,568) live in the London region (Graham et al. 2012; Graham 2013). All interviewees gave informed consent. For reasons of confidentiality, the interviewees are identifiable by pseudonyms, which I selected on an arbitrary basis. Still, if respondents had Jewish names, I allocated them different but equally Jewish names. The article will also mention their age bracket, status of affiliation, and Holocaust association where applicable.

I also conducted 16 expert interviews with employees, researchers and representatives of Jewish institutions as well as with academics active in Jewish-related fields of study. They were also allocated pseudonyms at random. I refer to the expert interviewees by their title, which is their real title, and surname in the text, as it is important to distinguish the experts I interviewed in an official capacity from the respondents, who spoke to me as a private person.

Regarding the observational part of the study, I have conducted most of the observations in densely Jewish-populated areas in North London, considering that the majority of Jews live in London and most of those London Jews live in the North-West London boroughs of Barnet, Hackney, Camden and Harrow (JPR 2000). Certain neighbourhoods in these boroughs have a Jewish population of 50-75\% (Graham et al. 2007). Conducting observations in such densely populated neighbourhoods provided me with a profound understanding of the social structure and texture of the Jewish community. I obtained access to observations such as synagogue services as well as social gatherings (e.g. Sabbath dinners and seminars) through gatekeepers such as rabbis and individuals met during observations and interviews. ${ }^{4}$ During my observational fieldwork, my reason for attendance was either communicated when being introduced to participants, or I communicated my researcher status in social interactions with participants such as by talking with them about my study as well as the reasons for my attendance.

\section{Remembered Traumas}

Participants often remembered traumas in which their family members died due to or survived anti-Semitism. The remembered traumas varied from discrimination and hostility against Jews to attacks and organized persecution throughout history. Over half of my interview sample mentioned close or distant family members enduring anti-Semitism in the past. These remembered traumas were mainly more recent ones, such as the Eastern European Pogroms, the

\footnotetext{
${ }^{4}$ As part of a full year of observation in different Jewish communities, I participated in the marking of every major holy day in the Jewish calendar at homes and different synagogues. I also visited people's houses, or met with them for food or drinks outside of the home at other times. I went to a bris (circumcision rite) and several birthdays, engagements and weddings. I did observations at the Jewish Learning Exchange, Jewish Book Week, the UK Jewish Film Festival, exhibitions about Jews and Judaism, Jewish theatre plays in London, youth group meetings such as Bnei Akiva gatherings, and at the Jewish cultural conference Limmud. I visited a Jewish primary school and went to talks, seminars, workshops and movies about Jewish topics at the Jewish Community Centre for London, London Jewish Cultural Centre, the Jewish Learning Exchange, synagogues, Universities, the Oxford University Chabad Society, and the Oxford University Jewish society. I spent time walking around Jewish areas, sitting in cafes and restaurants, and going to Jewish shops to observe members' interactions with each other. In terms of political observations, I visited the office of the Chief Rabbi and the United Synagogue Beth Din (rabbinical court), Tribe (the youth organization of the United Synagogue), the Board of Deputies of British Jews, the Institute for Jewish Policy Research, United Jewish Israel Appeal, Birthright Israel and the Community Security trust (CST).
} 
Holocaust, and the persecution of Jews in Argentina and Iraq. For example, Modern Orthodox Evan, in his 40s, whose parents fled from Baghdad, noted, "I have grown up in a Baghdadi family...you are conscious of the fact that there have been terrible times for Jews in Iraq." A few respondents also remembered earlier family traumas, such as the persecution of relatives in Portugal and Spain. For example, when unaffiliated Brianne, who was in her 50s, defined her identity, she argued:

It is about having some built-in understanding where Jews have come from, what's happening to the Jewish populations over the centuries and identifying with that... knowing that one branch of my family were expelled from Spain in the fifteenth century for being Jewish. I have quite a lot of Sephardies in my family so I know that that part of my family suffered persecution as far as that.

In narratives about their lives, however, such interviewees referred not only to the trauma experiences of their own family members but also to the trauma of the group as a whole. For instance, the unaffiliated Erica, who was in the same age bracket as Brianne, and whose parents survived the Holocaust and became refugees in England, felt Jewish because of her family's history of persecution. Still, she referred to the impact the Holocaust trauma had on her in general terms:

You'll find that's quite a common trait in the next generation of people who have suffered trauma that they become anxious... There's a part of me that separates me from others that is the Jewish part of me that defines very much my reaction to situations...I suppose in any political situation, there's always in the back of your mind, what is the Jewish angle to it. How does it affect being Jewish? It has been quite horrible with all the stuff going on in the Middle East. You do feel quite sort of anxious.

The Reform interviewee Richard, who was in his 20s, mentioned anti-Semitism in association with his anxiety about his physical safety in Britain and argued that it reminded him of the history of anti-Semitism, noting the Holocaust, the Eastern European Pogroms as well as the following memory of his family trauma: "My family had to leave Limerick in Ireland due to a pogrom in the early twentieth century, which was a religious-based pogrom, based on a local Catholic priest."

Interviewees also remembered traumas even if their family did not directly experience them and most importantly they could also remember them as their own trauma. The young unaffiliated Jim, who lived removed from the Jewish community and did not have any family involved in Holocaust, stated: "They [the Nazis] killed us." Modern Orthodox Ophra, who was in her 30s and whose in-laws went through the Holocaust and lost everything they owned, offered another example: "I am Jewish. The history of Jewish persecution is my history...The Nazis have tried to kill us. This is part of me." As the examples demonstrate many participants used subjective and personal pronouns such as $I$, us and we when talking about their group's traumatic experiences, already indicating the vicariousness of the trauma for them.

Interestingly, there was a subtle difference in trauma memory between secular and engaged affiliated participants. Secular Jews focused more exclusively on the memory of the Holocaust, whereas engaged affiliated participants tended to remember the Holocaust in association with earlier traumas, such as the enslavement in Egypt and their exodus over a hundred years later, the destruction of the First and Second Temple, the rededication of the holy Temple in Jerusalem at the time of the Maccabean Revolt of the second century BC, or the trauma of being nearly annihilated in the ancient Persian Empire. My findings suggest that engaged 
affiliated members' longer trauma memory can be related to their observation of holy days associated with those earlier traumas in the home, synagogues and Jewish (Sunday) schools. The enslavement in Egypt and the subsequent exodus of Jews is commemorated at Pesach, the first and second destruction of the Temple is remembered on the 9th of $A v$, the rededication of the Holy Temple in Jerusalem is commemorated in the festival of Chanukah, and the trauma of nearly being annihilated in the ancient Persian Empire is commemorated at Purim. In contrast, remembrance of the Holocaust among all types of participants is not unexpected considering the focus placed on the Holocaust in Jewish and non-Jewish education as well as mainstream culture such as movies, documentaries and exhibitions about the Holocaust. For instance, Jim, quoted above, who went to a non-Jewish school, said: "I did my A-level coursework on the persecution of Jews in the past 2000 years. Every country that I go to on our holiday, my mum used to take me to the Holocaust museum there, every single one. So I have been in Paris, Washington, New York, Rome, all over." The communication of past trauma can inform the personalization of the trauma memory in terms of creating awareness that one could have also suffered the trauma because of one's group membership, assisting in creating a vicariously felt trauma experience as the following sections demonstrate.

\section{Vicarious Traumatization}

The mechanisms elicited in response to trauma memory will be analysed independently of whether participants have family members that survived or were killed in Jewish traumas. This is because, as the last section has illustrated, interviewees who had family members involved in traumas did not only refer to the trauma of their family in narratives about their lives, but also the traumas of the whole group. Moreover, I did not find a significant difference in the mechanisms elicited by vicarious group trauma between the participants with family histories of Jewish trauma and those without them. To illustrate the lack of disparity between these two samples, the article will provide details of whether the quoted respondents had close family members that survived or were killed in the Holocaust where applicable.

Firstly, remembered traumas, especially more recent ones like the Holocaust and the Eastern European pogroms, elicited in many participants a feeling of anxiety; they felt anxious about having to undergo another trauma in the future because of their Jewishness. This trauma anxiety, in turn, informed their identification with the group. Anxiety is defined in this study as a deep-seated emotional state of discomfort and apprehension about future uncertainties.

For the Modern Orthodox interviewee Johanna, who was in her 20s and did not have close family who died in or survived the Holocaust, the Holocaust in conjunction with earlier traumas evoked anxiety, which informed her sense of group belonging and accordingly identity:

I can't really disassociate the Holocaust from my images of anti-Semitism throughout Jewish history...it's been up and down. Sometimes we've been absolutely great like now in Britain. Jews are at a height of doing fine, and then we'll be the lowest of low, and there will be crusades or a pogrom or something...Anyone who is Jewish can be a victim of anti-Semitism. So it makes me feel bonded with them [Jews] in that way.

This interviewee's trauma anxiety was also connected with hypervigilance through the perceived threat of anti-Semitism: 
It makes me more cautious on the streets...I have an absolute terror of being hurt...it separates me from the non-Jewish world and strengthens and connects me more with the Jewish people. It also pushes me more towards Jewish people and away from nonJewish people. It makes me more suspicious and more distrustful.

This quote highlights how the mechanisms in response to this type of trauma memory can interrelate and the importance of group membership in experiencing vicarious traumatization and thus vicarious group trauma.

Even the very unaffiliated Alonso, in his 50s, who grew up in Argentina and had family members suffering anti-Semitism there, claimed that his group shares an inherent trauma anxiety, which he argued is related to him being connected with other Jews in the past and present.

There is a sense of national anxiety in Jews...If someone would say something very bad about Israel; I would react in a different manner than you are going to react, because obviously you feel immediately what is actually touched is something that...is more in the limbic system. That is where the emotions are located and associated with a much more primitive way of being. A comment like that is going to touch the trauma that has gone on for 2000 years, so I cannot react like you... The trauma is actually connected to a historical part of being part of a group. So, for instance, let's say that Hitler would have actually won. I'm telling you today that I wouldn't be here talking to you so it can actually not be traumatic for me, but that's also why it is.

This quote also illustrates that anxiety can be associated with other asserted mechanisms, in this case the perceived threat of a future trauma. The fact that this particular unaffiliated interviewee related his trauma anxiety to the continuous persecution of Jews over the years makes him an exception to a strong pattern; most secular Jews in my ethnographic sample related their anxiety to the Holocaust alone. This can be associated with the fact that secular members do not tend to follow any or many ethno-religious rituals related to the commemoration of earlier traumas, but are exposed to diverse information about the Holocaust in their daily lives, e.g. through family, the media or schools.

Whereas some participants, such as those quoted above, expressed anxiety in relation to vicarious group trauma very overtly, others expressed their anxiety more subtly in narratives about anti-Semitism or Israel. For instance, when I asked the community-engaged Modern Orthodox Steve whether it is still important to fight against anti-Semitism, he answered: "It's imperative...because it's based on forethoughts [of another trauma]." Similarly, Rudolph, in his 60s, who, unlike Steve, had close relatives going through the Holocaust, said when talking about anti-Semitism in Britain:

You can never discount that [meaning another trauma happening to Jews]. One should never discount that. There have been problems for Jews in the last few years in England...Bad things do happen to Jews in England. Synagogues are being firebombed. ${ }^{5}$ People are being attacked in the street... Will it ever go back to twelfth century York?

\footnotetext{
5 There was an arson attempt on the Brondesbury Synagogue in Willesden, North-West London on the fourth of January 2009 in response to Israel's operation on December 27 2008. Assailants attempted to set fire to its entrance door. The interviewee may have recalled the arson attempt as a firebomb attack as the Jewish Chronicle's headline about the event was "bid to firebomb synagogue as protests grow” (Silver 2009).
} 
Interestingly, a majority of respondents, mainly those who were affiliated, expressed their trauma anxiety in view of possible safety options: namely having Israel as their "safe haven" (Zachariah, Modern Orthodox, 20s) or "insurance policy" (Hugh, Modern Orthodox, 50s); a place that would provide Jews with security in the event of another trauma. Even the midtwenties Modern Orthodox Jonah, who did not have any direct Holocaust link and who was less involved in the community, felt comforted by the existence of Israel:

I feel more secure with the fact that I have this insurance policy of Israel...Every Jew can go to Israel, no questions will be asked. They get citizenship immediately. ${ }^{6}$ They allowed in a million Russians in 1991 and these Russian Jews were very privileged... When people try to get rid of it, it makes me very uncomfortable. It makes me think actually when there were problems in Ethiopia or Yemen...they [Israelis] actually airlifted them in...The Israeli air force went in and got them out...I like having Israel for that reason.

This particular finding should be read in light of the historical context in which political Zionism used the Holocaust and Jews' existing trauma anxiety as a justification for the foundation of Israel (Novick 1999) and more importantly that there is support from Jewish institutions for the State of Israel. Although synagogues of the Progressive movement may not be as supportive of Israel as the Modern Orthodox movement and its leading institution, the United Synagogue, most synagogues will still be generally pro-Israel. For instance, the United Synagogue, to which most of the affiliated members in Britain belong (Graham and Vulkan 2010), "strongly believe[s] in the centrality of Israel in Jewish life" (JLC 2016).

Secondly, trauma can sensitize people to perceive potential dangers in situations or things in their environment. Accordingly, I found that many participants perceived threats from gentiles or non-Jewish entities based on the traumas their group had to endure in the past. Some participants perceived danger in the form of prospective actions from states such as Iran or terrorist groups such as Hamas. They drew on evidence from previous Jewish traumas to validate their perceptions, suggesting that threat perceptions are fuelled by vicariously experienced group traumas. For example, the young Modern Orthodox community-involved Alon, without close relatives experiencing the Holocaust, opined:

I get worried about what's happening in Iran...There's going to be another threat to Jewish people and it is how Iran promises to wipe out Israel off the map...It probably just means that I am paranoid...X-million Jews would be killed for no reason like in the Holocaust...being Jewish and having that knowledge of history and knowledge of persecution...it does add an extra dimension of worries in the equation.

The quote illustrates the importance of a personal association with the group in feeling perceptions of threats in the present because of trauma to Jews in the past.

Several participants perceived anti-Semitism due to Israel's domestic policy with regards to the occupied territories as threatening because it reminded them of traumas experienced by their group in the past. In particular affiliated participants' expressed worries about a perceived increase in anti-Semitism following the airstrikes and ground invasion in Gaza in December 2008. This threat perception was often expressed very subtly in responses to the interview

\footnotetext{
${ }^{6}$ The Law of Return is legislation enacted by the Israeli government in 1950 and amended in 1970 in response to Jewish persecution over the centuries, particularly the Holocaust. It gives all persons of Jewish ancestry (e.g. even grandchildren of Jews) and their spouses the right to move to Israel and get Israeli citizenship (Richmond 1993).
} 
question about whether it is important to fight against anti-Semitism. For example, the community engaged Reform interviewee Robin, in his 30s, who did not mention family relations involved in Jewish traumas, first distanced himself from the notion that it was still important to fight against anti-Semitism by asserting that he does not think the Holocaust could happen again: "I am not worried that I will be physically in danger in this country." However, later in the interview when he talked about the recent Gaza conflict, it suddenly appeared that Robin did have a threat perception, a threat that was for him connected to the Holocaust and to even more recent attacks on Jews, such as the attack on a Chabad centre in Mumbai in November 2008: ${ }^{7}$

It [anti-Semitism] doesn't make me feel massively insecure as a Jew in Britain. It doesn't feel it's at that stage "yet." Only very, very recently have I become more personally worried because I think during the Gaza conflict some of the rhetoric became quite scary. I do occasionally worry about security in Jewish buildings...At some point there probably will be a terrorist attack on a Jewish target in Britain...It will happen...In Mumbai, they attacked the Lubavitch home...We are not anywhere near that [the Holocaust]...I worry what's gonna happen in Israel and how that's gonna impact on Jews...I do support the CST financially. ${ }^{8}$

Robin's attempt to distance himself from a perception of threat in association with the vicarious group trauma indicates that he consciously understands that such a mechanism can be elicited in response to this memory. ${ }^{9}$ His apparent inability to prevent himself from experiencing it points to the power of this personalized trauma memory.

Moreover, in several conversations perceived threat of another trauma for Jews was expressed in a very offhand manner. After a Sabbath lunch in the beginning of 2009, a Modern Orthodox male in his early twenties talked about wanting to make Aliyah (i.e. move to Israel). He spoke mainly about the positive aspects of living in Israel, but, surprisingly, while getting ready to leave, he added: "It's getting dangerous here. Anti-Semitic attacks are increasing in Britain and all around the world. Look at France, all the Jews are leaving... They move to Israel." Without vicarious group trauma it would be unlikely for such a strong statement to be asserted. Considering that the Gaza conflict had erupted not long before and that members in the community talked about the increase in anti-Semitism due to Israel's military actions, this particular threat response is understandable.

When talking about previous traumas, some interviewees such as the young Modern Orthodox interview Josie, who did not have any direct Holocaust family connections, made

\footnotetext{
${ }^{7}$ The Rabbi Gavriel and Rivkah Holtzberg, the directors of Chabad-Lubavitch of Mumbai, were killed during the terrorist attack by Islamist terrorists on their centre in Mumbai on November 262008.

${ }^{8}$ The CST is the Community Security trust. It is a charitable organization funded by the Jewish community to provide representation and advice for the community on matters of security and anti-Semitism; e.g. provision of a yearly anti-Semitic discourse and incidents reports. Its aim is to protect it from "bigotry, anti-Semitism and terrorism" (CST 2011). This organization provides physical security, training and advice for the protection of British Jews.

${ }^{9}$ Crime statistics show that physical and verbal attacks against Jews are relatively rare in Britain (CST 2010). From 2003 to 2013, there has been an average of 2 extreme cases of violence involving serious physical harm or a threat to life, 90 assaults, 66 damage and desecration incidents, 37 threats, 367 incidents of abusive behaviors against Jews and 24 anti-Semitic cases found in literature (CST 2014). Comparing the average number of antiSemitic incidents from 2003 to 2013 - 586 incidents (CST 2014) - to the number of Jews by religion living in Great Britain-269,568 according to the 2011 Census (Graham 2013) -results in the statistic that 1 in 460 members experiences anti-Semitism in this country. The discrepancy between the relatively low number of antiSemitic incidents and the prevalence of a threat perception among participants suggests that talking about and looking out for threats can reinforce a threat perception.
} 
a link to talk about current threats to Jews, which demonstrates the association between the two even more clearly:

We have that [the Holocaust] in common. Innately you feel threatened, we know the history of the Jewish people and it's hard for the Jewish people; they've always had problems...In every generation it happens, we have had Hitler and the Nazis, now we think there's a growing threat whether it's the BNP [British National Party] or Islamic Extremism coming out publically saying they will kill the Jews, for example. There's this feeling there and you can't really ignore it.

It also came to my attention that members often look out for signs of threat to their groupsuch as negative news about Israel or anti-Semitism - in the mainstream newspapers or in online media. For instance, the Liberal Anthony, in his 60s, whose family has been in the country for centuries, and subsequently would not be expected to have a threat perception, expressed his perception in this way: "If you are Jewish, you look out for what they write about Jews. If they write something bad about Israel, you just see it. Such news stands out to you. It wouldn't stand out to you [non-Jews]." Anthony felt that Jews were, as he called it, "hardwired" to notice such reports or comments because of their personal and, hence, emotional association with the trauma memory.

Some participants also noted that this threat perception also made them sensitive to the way gentiles talk about Jews or topics relating to them in their presence. Accordingly, a perception of threat can be expressed in sensitivity to possible threats and, as shown below, can also shade into hypervigilance. For instance, the unaffiliated Eric, in his 60s, who grew up with his mother and two aunts, who all survived concentration camps, noted: "You just hear when people talk about Israel or Jews. It's like you're always on guard. You always want to know whether people are anti-Semitic; whether there's a threat for us. It's in us. History has taught us to be on the lookout."

Negatively perceived comments about the group or Jewish issues, told by gentiles or written in the broadsheet press, as well as online, were often interpreted by participants as a sign of anti-Semitic sentiments or an increase of it amongst non-Jews as well as an indicator of threat to Jews. For example Adena, a Modern Orthodox in her 20s, said:

Even though I was lucky enough not to have had my family-like my close family-directly affected by the Holocaust, I think that you can never lose sight of the fact that I think you're living in a country at the mercy of that country....I live in a very benevolent country; I'm very lucky. Could that change in the future? Yes...Jews in Germany were very comfortable before the War, there was no one more German than the Jews, completely integrated into society, and I don't know if we'll ever lose sight of the feeling that times could change, and that we can't depend on it.

Later in her interview, she gave an example of how the perception of threat in response to her vicariously felt trauma experience can manifest:

Jews are very conscious of anything negative or high profile about anybody who is Jewish. For example, Bernard Madoff...Immediately non-Jews will think "he's Jewish" [derogatory tone] and immediately all the stereotypes will come up: Jew, wealthy, fraud, thief, criminal, all Jews are rich and are thieves... With the current economic climate, people need to have a scapegoat and the fear is that Jews will become the scapegoat again because of people like that. 
Thirdly, the perception of threat can even take the form of hypervigilance, a state of constant alertness. It can be expressed in hyperawareness and hypersensitivity to threat indicators. Threat indicators are cues that are perceived as being negatively related to one's group; through them threat beliefs can be continually reinforced. Some participants directly referred to their own or others' hypervigilance as paranoia or over- or hyper-sensitivity such as the middle-aged Masorti interviewee Johnda: "You are suspicious [because of the Holocaust]; a constant fear that they [non-Jews] don't like you... It's the identity of Jews. I cannot believe that there are Jews who don't feel this particular hypersensitivity."

Adah, a Modern Orthodox woman in her 20s, who did not have immediate relations who died in or survived the Holocaust, gave a poignant example of such hypervigilance:

We are all victims of anti-Semitism [ironically said]...Anti-Semitism won't go away and it might be disguised by anti-Zionism or anti-this or anti-that...I think like for me the Holocaust is not prevalent, it doesn't cut in my Jewish identity, but for a lot of people it is...A friend of mine got a ticket and he said that the officer was, for sure, anti-Semitic. And I was like "No, you were driving at 50 miles an hour in a 30 zone. What do you expect?" He was like "No, no, he was anti-Semitic; he could have let me off." It's victimization. People think that everything that happens to them is because they are Jewish such as "I didn't get the job because they thought I was a Jew"...Everyone who is rude to them is so because they are Jewish.

Another example of hypersensitivity surfaced one Sabbath afternoon in a group conversation about anti-Semitism over the centuries. A Modern Orthodox in his mid-twenties recounted a story about how his hypervigilance due to vicariously experienced anti-Semitism manifested itself in his life. He had just started a new job as an investment banker in the city. Because he wore a kippah (a skullcap) and had requested to have certain working days off for major holy days, he was recognizably Jewish. He felt that he had to work extra hard and be better than others in order to prevent negative attitudes towards him from surfacing. His anticipation of anti-Semitism was informed by the history of discrimination against Jews. Right from the start of his new employment, he felt that one colleague in particular was anti-Semitic. He started, as he called it, "an anti-Semitism tally," noting down every instance in which he perceived that the colleague was racist towards him. After having gathered enough evidence, he decided to talk to other colleagues about this employee's behaviour towards him. He realized that his perception was, as he labelled it "paranoia," when he found out that this person was equally rude to others and thus "just a bad person."

The unaffiliated Avery, 50s, who was not, at the moment of the interview, involved in the community and did not have a direct Holocaust link, but had a strong community background, referred to the inescapability of his Jewishness due to the Holocaust memory when explaining his sense of anxiety and hypervigilance:

I'm full of Jewish blood. You are born into a club. It's not a club that you can leave even if you choose to because the blood is in you... with Jews there's this warmth, which isn't with British people... There's always that fear that...they might turn against you because you are Jewish. We are brought up in our childhood to expect it... There might be a point to persecute me in the future...As long as there are Jews there will be anti-Semitism. It [being Jewish] is something that you feel could be used against you...Images that come up: Germany in the 1930s, organized anti-Semitism. It's about never having to drop your guard by believing that these people would never use this tool against you. 
The quote illustrates, that even for secular members, threat perception can morph into the more intensified form of hypervigilance. Still, as this section has demonstrated, traumatization symptoms were more prominent and intense among community-involved Jews, especially among engaged affiliated participants.

\section{Institutional Focus on Threat}

There is an institutional focus on threats to Jews that can assist in the construction of a sense of anxiety, threat perceptions and, by extension, hypervigilance for those exposed to it - that is, mainly community-involved Jews and particularly, affiliated community-involved Jews. Community-involved affiliated Jews are generally more engaged in Jewish religious and non-religious structures and thus more exposed to narratives about past and present threats to Jews, which, in turn, can explain why vicarious traumatization symptoms are more prominent and intense among them than they are among less engaged affiliated and unaffiliated Jews.

Through observational research I found that both non-religious and religious Jewish organizations, such as schools, which affiliated, but also community-involved unaffiliated Jews tend to attend (Graham et al. 2014; Rocker 2014), place an emphasis on communicating past and present threats to their members. This cannot only make the trauma more immediate for them but can also inform the construction of traumatization symptoms and accordingly vicarious group trauma. For instance, unaffiliated Claire, who was in her 20 s without any close family experiencing the Holocaust, noted in terms of schools:

It [meaning Jewish trauma] started with like the blood libels, Pogroms in Eastern Europe and in a way like we are taught [in Jewish educational institutions] as if it's always led up to the Holocaust... They [teachers] tell you Jewish persecution will never end and that others are always out to get you.

Claire, who grew up in a middle-of-the-road Orthodox home, did not identify with this siege mentality and related her lack of vicarious trauma symptoms to the fact that she had religiously and physically distanced herself from the community since going to university and living away from home.

Both types of organizations arrange many events to inform members about threats to them. This includes events about anti-Semitism in the present that often connect it to anti-Semitism in the past; for example events about anti-Semitism in regard to Israel, which has been coined as the new anti-Semitism (Klug 2003). There are various lectures, seminars, workshops and movie screenings that focus on threats to the group at places such as synagogues, university Jewish societies, Chabad society centers and other cultural and political group meetings. Holocaust survivors and now also their children give talks within the community about the experience. One reason often given for doing so is to raise awareness that another trauma like the Holocaust could be prevented. The academic Dr. Goldstein contributed to this observation: "I was actually discussing a possible program of talks at one of the large United Synagogue Communities and I found it fascinating that they said they can only guarantee a good turnout when there's a discussion on anti-Semitism." This quote, furthermore, indicates that institutions place importance on perpetuating traumatization 
symptoms. The fact that there is an audience that wants to hear about threats suggests their success in this regard.

Synagogues, like schools, were found to be key places where threats are accentuated. Such institutions provide regular interaction platforms where members meet and in this way are particularly effective in supporting the construction of traumatization symptoms among its members. In the synagogues in which I did observations, the rabbis not only focused on the observation of past threats to Jews, such as through the marking of holy days associated with those earlier traumas, but also on possible present threats to the group in their communication with synagogue members. At the time of the European Parliament elections, for instance, a Modern Orthodox rabbi urged his congregation during the Sabbath morning service to vote so that the BNP would not get any seats, to prevent another trauma like the Holocaust. Such statements can reinforce the importance of the trauma and simultaneously strengthen perceptions of threat among Jews, as illustrated in the following comment by Adah, who was involved, amongst other Jewish institutions, in this synagogue community, about a week after hearing the rabbi's speech: "Look at the European Elections now, the BNP have got a strong chance of getting seats... and that's worrying. It is worrying because that's like how Hitler came into power. It's happening before our very eyes."

Adah was quoted earlier as saying that the Holocaust does not have an impact on her, but here we see that this memory elicits a threat perception in her. As with Robin, this demonstrates that although there can be a cognitive understanding of the mechanisms that can be elicited in response to the transmitted trauma, this does not necessarily inoculate people from experiencing them, particularly if they engage with community institutions. Such evidence also suggests that the impact of vicarious group trauma is strong enough to bypass a person's rational thinking.

The interview with Adah was conducted in a Jewish café. While I was talking to her, a Board of Deputies of British Jews delegate came to our table to encourage us to vote in the upcoming election. The conversation between my interviewee and the delegate turned to how thankful she was for his efforts so that the BNP would not win any seats. This caught the attention of a male Jewish immigrant from Israel in his mid-thirties sitting next to us. He interrupted them saying: "No one is here for us." Adah started a conversation with him in Hebrew and then turned to me to argue: "See that's the general Jewish attitude. He says, 'They are all as bad as each other, they all want to kill us, what do I care? So if I vote Labour, Conservative or BNP, they all want to kill us, so what difference does it make?'" Adah then said to me: "Victim mentality. Perfect example. They believe no matter who gets into the European parliament; they all want to kill us." This conversation illustrates how easy it is to be confronted with an institutional traumatization mediator - as in the form of this delegatewhen in a Jewish area. The described situation shows that institutional agents can assist in the construction and reinforcement of members' sense of perceived threat and, by extension, hypervigilance. This would be unlikely to occur, however, without a sense of group affiliation. Moreover, it highlights that non-religious institutions also focus on possible threats posed to the group.

Regarding the focus on threat by non-religious institutions, the Jewish community in Britain even has its own security organization called the Community Security trust (CST). CST represents and advises the community on matters of security for Jews. CST also monitors hate crimes against members and possible terrorist threats (e.g. CST 2004). According to the CST representative I interviewed, Mr. Finkelstein, it is even important to monitor threats posed to the group in other countries, as those threats could spill over into Britain. The Holocaust was 
referenced as an example of how threat can spread. This illustrates how vicarious group trauma can even affect organizations' outlooks, in this case making it an institutional goal to inform the community about threats and to safeguard it through prevention work. The fact that the CST is a charitable organization, funded primarily by Jews themselves, implies not only that there is a considerable level of perceived threat within the community in Britain, but also that this community assists in perpetuating this institutional focus on threat.

The CST particularly focuses on threat prevention by offering security advice and training for Jewish schools, synagogues and other communal institutions, and to Jewish individuals such as pupils and university students. Some of the participants mentioned that they did not feel comfortable wearing Jewish symbols outside of the community because they did not want to fuel anti-Jewish sentiments and be a target of anti-Semitism. The following example shows how such threat perceptions can be reinforced among members by an institutional focus on threat:

I didn't feel secure wearing T-shirts with Israeli writing on them [at my university]. I felt like people would make offensive comments. The CST advised us against it or tried to facilitate us to do it. The CST always tries to allow the community to operate as much as possible as it wants to do. So rather than saying "Don't wear that T-shirt," they say "Wear that T-shirt and we'll make sure that someone is here so that you can." (Aron, community-involved unaffiliated, 20s)

The CST also advises Jewish institutions on appropriate security measures to prevent antiSemitic incidents, such as using CCTV cameras, security alarms, and most importantly, security personnel on their premises. For instance, after the Gaza invasion in 2008, the CST advised Jewish institutions to increase their security measures. The impact this had on members can be seen in that the Modern Orthodox community-involved Dr. Goldstein who argued that "the Holocaust is not just a shadow" and that it "makes Jews want to battle against anti-Semitism" - subsequently agreed with the increase of security in her daughter's Jewish primary school as a response to the Gaza incursion:

They have employed an extra security guard. They have already got two full-time security guards and they have changed the closing time of the school. It used to be that the younger children would finish at three thirty and the older children at four. Because that meant that the school gates were opened until ten past four, so for a whole forty minutes, which was seen to be too big a security threat, they have now changed it, half that gap and made the infants finish not until ten to four so that the school gates would only be opened for twenty minutes, which I find to be an unbelievably radical move. One assumes that this is because of a real perceived threat because that requires an awful lot of commitment from parents and teachers to implement.

The fact that the school and parents complied with the security advice and implemented additional security measures illustrates the community's heightened level of perceived threat and, by extension, acute sensitivity to threat indicators, as well as institutions' power to accentuate such threat - a power that can be justified because of the Holocaust.

The strong influence of the CST's focus on threat monitoring on Jews' sense of threat perception is further illustrated in the following quote by Alon, who helps to secure the premise of his local synagogue during services:

People are being trained by the CST. They are having emergency buzzers that alarm the police...People get nervous when people drive past [the synagogue] slowly and take 
photos...so you have to be aware and have heightened security measures. I think there is

a serious, serious threat.

In regard to the impact of security advice by institutions such as the CST, the young Modern Orthodox - involved Saul, who shortly after the interview became quite detached from the religious community and moved abroad to experience a liberal non-Jewish life, gave a critical account:

If you listen to the CST you'd probably get quite worried, and you'd be worried when you walk out on the street, although they're trying to get people to feel safer about things...I don't like what it does to you as a person. If you think that people are out there to get you, it makes you a really nervous wreck, and it just makes you not feel part of society.

This suggests that while security measures (e.g. CST patrols on holy days in Jewish neighborhoods) function mainly as deterrents against low-level, less organized attacks against the community and provide an image of safety, their existence can also reinforce the perception of being under constant threat and thus hypersensitivity as well as fuel anxiety.

Furthermore, my observational evidence suggests that Jewish news organizations focus on threats to Jews as they frequently report about anti-Semitism in the past and present. This was also picked up by some of the participants, mainly secular members who have grown up in the community by living in Jewish neighborhoods and attending Jewish schools and/or synagogues. These participants argued that such intense focus on threats to members by the Jewish media can assist in bringing the trauma of the past into the present and accordingly can reinforce members' existing anxiety, threat perceptions and hypervigilance:

When I read the Jewish Chronicle, there are always tales about anti-Semitism, there is always something about anti-Semitism so one is reminded of these things and you don't need the Holocaust [said ironically]. (Ruben, Modern Orthodox, 60s)

If you read the Jewish Chronicle on a daily basis you start thinking another Holocaust is about to happen. (Josephine, Masorti, 40s)

To sum up, the findings indicate a focus in the Jewish community and particularly by its institutions, on threats to the group, which stands in association with vicarious group trauma. This focus on threat can assist in the construction and reinforcement of anxiety, threat perceptions and, by extension, hypervigilance. It can accentuate the trauma memory by making the trauma more immediate for members. Considering that most of the less communityengaged Jews were not exposed to constant and multiple traumatization mediators because of their physical and social distance from the community, it can be inferred that the traumatization mediators provided by community institutions have a strong impact only on engaged Jews, particularly on affiliated involved Jews. This can explain why vicarious traumatization symptoms were found to be less prominent and intense among less community-involved Jews.

\section{Conclusion}

This article has developed a sociological theory of vicarious group trauma. The theory purports that people can feel a threatening event and abuse that were inflicted on members of their social group as if this had happened to them. Individuals identify with the traumatic incident or abuse personally as members of their group so that it can be an emotional experience for them. 
Through a personal association with the trauma as members of the group, a historical fact of group trauma can become an emotional trauma experience for them strong enough to bypass rationality and elicit strong emotions and perceptions, i.e. vicarious traumatization. We speak of vicarious group trauma when many members of a collectivity can be attested to have or they themselves feel as if they have a visceral identification with their group's trauma; reflected in signs and signals of traumatization. In this way, vicarious group trauma can inform members' sense of belonging to the group and, therefore, their identity.

Using the method of ethnography, this article applied the theory by exploring how transmitted group traumas manifest themselves in the everyday experiences of Jews in Britain and, in this way, impacts their identification with the group. To do so, the article showed first which traumas Jews remembered and concluded that group traumas are remembered selectively, termed "chosen trauma" by Volkan (2001). Secular participants tended to remember only the Holocaust, which was proposed to be related not only to the communication of the event through personal family stories but also more generally through mainstream culture and education. For example, the Holocaust Education Trust reports that Holocaust education is generally part of the national curriculum in British schools even though it is not a formal requirement in Wales, Northern Ireland, Scotland or in independent schools in England (HET 2011). There are also many exhibitions (e.g. the Holocaust exhibition at the Imperial War Museum), renowned plays, blockbuster movies, and award-winning documentaries about the Holocaust. Devout affiliated members had a propensity to also remember earlier Jewish traumas, such as the enslavement in Egypt and their exodus over a hundred years later. I suggested that this was related to the observation of holy days associated with those traumas in synagogues, Jewish schools and homes in addition to personal family stories. For instance, the enslavement in Egypt and the subsequent exodus of Jews is commemorated at Passover. At the Passover Seder, a ritualistic dinner, participants are required to view themselves as if they came out of Egypt. Passages like the following ones are read aloud: "We were slaves to Pharaoh in Egypt, but the Lord our God brought us out" (Deuteronomy: 6-21), and, "You shall tell your son on that day, it is because of what God did for me when I went forth from Egypt" (Zerubavel 1996: 290, Exodus 13:8). In this way, the article showed that there are not only Jewish institutions including the family but also non-Jewish ones that assist in the transmission of trauma memory and highlight members' difference from gentiles, which in turn can inform identification with the group.

The article then illustrated that the vicarious sensation of traumatic group experiences can create anxiety and elicit perceptions of threat and, by extension, hypervigilance, which can inform group identification. It is well-documented in the psychology literature that transmitted trauma can elicit these traumatization symptoms in people who come into contact with trauma victims over a prolonged period of times, such as family members or therapists (McCann and Pearlman 1990); case studies have been written about the traumatization symptoms found in second and thirdgeneration offspring of Holocaust survivors (Danieli 1985; Prince 2009). My study adds to literature in this area as there is little research exploring secondary traumatization among Jews on the grouplevel, including Jews who have not been in close contact with trauma survivors. The findings resonate with research such as that by Hirsch and Chaitin (2010), which describes Jewish-Israeli young adults, with and without family connections to Holocaust survivors, as fearful because of the Holocaust. Similarly, Lazar et al. (2008) relate to trauma anxiety by asserting that it exists among Israeli Jews, including those without direct connection to Holocaust survivors, in the form of needing Israel as a place of safety. Their article connects Jews' association of Israel as a safe haven with political Zionism's focus on the need for a sovereign Jewish state by arguing that the lack of it "was one major contributing factor that Jews in Europe, prior to and during the Holocaust, were singled out for massive persecution" (Lazar et al. 2008: 116). 
Lastly, the article showed how group institutions can contribute to the construction and reinforcement of not only trauma memory but also of vicarious group trauma. It demonstrated that there is an extant institutional focus on past and present threats to Jews, which can assist in the creation and reinforcement of traumatization symptoms among members. The article found that traumatization symptoms, particularly perceptions of threat and hypersensitivity, were prominent among community-involved Jews, and especially among affiliated engaged members. Their level of involvement in the social structure allowed for increased exposure to constant and multiple institutional traumatization agents such as security guards in front of synagogue. Thus, the findings indicate that institutional platforms of a group's social structure provide a powerful instrument for informing and perpetuating trauma memory and, with it, vicarious group trauma.

The article adds to sociological research that offers largely theoretical analyses regarding the transmission of the historical fact of memory and how the memory must be presented in public for it to become a social trauma (Assmann 2006; Eyerman 2011; Eyerman et al. 2011). My work has provided a systematic empirical account of the impact transmitted group trauma can have on the emotions and perceptions of members independent of any direct relation or contact with a survivor of the group's trauma, and the role the social structure with its institutions plays in this regard. In this way, the findings can be applied more widely to other groups with a history of trauma. Scholars may seek to explore the extent to which vicarious group trauma is present in other minorities. Case studies could include the impact of the times of slavery on AfricanAmericans in the United States or the partition of Punjab in 1947 and the 1984 attack on the Golden Temple for Sikhs and the effects of more recent traumatic experiences such as the conflict in Syria and Rwandan genocide on the respective diaspora communities. All of those traumas have been communicated through institutional mechanisms, such as the media and cultural organizations like museums. For example, the memories of the Sikh's traumatic experiences are used in discourses by organizations and community elites in the diaspora to maintain and strengthen members' group belonging (Barrier 2006; Tatla 2006; Jacobsen and Myrvold 2011). Thus, these group traumas would be worth an examination in view of how the social structure with its institutions assists in their perpetuation within and across generations.

Acknowledgments The author thanks Random House, St Catherine's College and the Sociology Department of the University of Oxford for the financial support in order for me to conduct this study as well as Michael Biggs, Shana Cohen, Gabriella Elgenius, Miri Freud-Kandel, Thomas Grund, Anthony Heath, Brian Klug, Avner Offer and the journal's reviewers for valuable comments.

Open Access This article is distributed under the terms of the Creative Commons Attribution 4.0 International License (http://creativecommons.org/licenses/by/4.0/), which permits unrestricted use, distribution, and reproduction in any medium, provided you give appropriate credit to the original author(s) and the source, provide a link to the Creative Commons license, and indicate if changes were made.

\section{References}

Alexander, Jeffrey C. 2004a. On the social construction of moral universals. The "holocaust" from war crime to trauma. In Cultural trauma and collective identity, eds. Jeffrey C. Alexander, Ron Eyerman, Bernhard Giesen, Neil J. Smelser, and Piotr Sztompka, 196-263. Berkeley: University of California Press.

Alexander, Jeffrey C. 2004b. Towards a theory of cultural trauma. In Cultural trauma and collective identity, eds. Jeffrey Alexander, Ron Eyerman, Bernhard Giesen, Neil J. Smelser, and Piotr Sztompka, 1-30. Berkeley: University of California Press.

Alexander, Jeffrey C., Ron Eyerman, Bernhard Giesen, Neil J. Smelser, and Piotr Sztompka. 2004. Cultural trauma and collective identity. Berkeley: University of California Press. 
Assmann, Aleida. 2006. Der lange Schatten der Vergangenheit: Erinnerungskultur und Geschichtspolitik München: C. H. Beck Verlag.

Barrier, Norman, Gerald 2006. Trauma and memory within the Sikh diaspora: Internet dialogue. Sikh Formations: Religion, Culture, Theory 2 (1): 33-56.

Ben-Amos, Avner, and Ilana Bet-El. 1999. Holocaust day and memorial day in Israeli schools: Ceremonies, education and history. Israel Studies 4(1): 258-284.

Berman, Judith E. 2004. Holocaust commemorations in London and Anglo-Jewish (dis-)Unity. Journal of Modern Jewish Studies 3(1): 51-71.

Caruth, Cathy. 1996. Unclaimed experience: trauma, narrative, and history. Baltimore: Johns Hopkins University Press.

Cooke, Steven. 2000. Negotiating memory and identity: The Hyde Park holocaust memorial, London. Journal of Historical Geography 26(3): 449-465.

CST. 2004. The community security trust: Terrorist incidents against Jewish communities and Israeli citizens abroad, 1968-2003. London: Community Security Trust.

CST. 2010. Antisemitic incidents report 2009. London: Community Security Trust.

CST. 2011. CST - Protecting the Jewish Community. www.thecst.org.uk/. Accessed 12 November 2014.

CST. 2014. Antisemitic Incidents Report 2013 London: Community Security Trust.

Danieli, Yael. 1985. The treatment and prevention of long-term effects and intergenerational transmission of victimization. A lesson from holocaust survivors and their children. In Trauma and its wake, ed. Charles R. Figley, 278-294. New York: Brunner/Mazel.

Eyerman, Ron. 2011. The cultural sociology of political assassination: from MLK and RFK to Fortuyn and Van Gogh. Palgrave Macmillan: Cultural sociology. New York.

Eyerman, Ron, Jeffrey C. Alexander, and Elizabeth Butler Breese. 2011. Narrating trauma: on the impact of collective suffering. Boulder: Paradigm.

Figley, Charles R. 1983. Catastrophes: An overview of family reaction. In Compassion fatigue: Coping with secondary traumatic stress disorder in those who treat the traumatized, eds. C.R. Figley, and H.I. McCubbin, 1-20. New York: Brunner/Mazel.

Freud, Sigmund. 1932. Moses and Monotheism. International psycho-analytical library, vol. no 33. London: Hogarth Press.

Graham, David. 2013. 2011 census: Thinning and thickening. London: Institute for Jewish Policy Research.

Graham, David, and Daniel Vulkan. 2010. Synagogue membership in the United Kingdom in 2010. London: Institute for Jewish Policy Research.

Graham, David, Marlena Schmool, and Stanley Waterman. 2007. Jews in Britain: A snapshot from the 2001 census. London: Institute for Jewish Policy Research.

Graham, David, Jonathan Boyd, and Daniel Vulkan. 2012. 2011 census (England and Wales): Initial insights about the UK Jewish population. London: Institute for Jewish Policy Research.

Graham, David, Daniel Staetsky, and Jonathan Boyd. 2014. Jews in the United Kingdom in 2013: Preliminary findings from the national Jewish community survey. London: Institute for Jewish Policy Research.

HET. 2011. Holocaust education in the UK. London: Holocaust Educational Trust.

Hirsch, Marianne. 2008. The generation of postmemory. Poetics Today 29(1): 103-128.

Hirsch, Tal Litvak, and Julia Chaitin. 2010. "The shoah runs through our veins": the relevance of the holocaust for jewish-israeli young adults Idea 14 (1).

Jacobsen, Knut A., and Kristina Myrvold. 2011. Sikhs in Europe: Migration, Identities and Representations. Farnham: Ashgate Publishing Limited.

JLC. 2016. United Synagogue. http://www.thejlc.org/portfolio/united-synagogue/. Accessed 13 May 2016.

JPR. 2000. A Community of Communities: Report of the commission on representation of the interests of the British Jewish community. London: Institute for Jewish Policy Research.

Kellerman, Natan P.F. 2001. Psychopathology in children of holocaust survivors: A review of the research literature. Israel Journal of Psychiatry and Related Sciences 38(1): 36-46.

Klug, Brian. 2003. The collective Jew: Israel and the new antisemitism. Patterns of Prejudice 37(2): $117-138$.

Kugelmass, Jack. 1996. Missions to the past: Poland in contemporary Jewish thought and deed. In In Tense Past: Cultural Essays in Trauma and Memory, eds. Paul Antze, and Michael Lambek Lambeck, 199-214. New York Routledge.

Landsberg, Alison. 1997. America, the holocaust, and the mass culture of memory: Toward a radical politics of empathy. New German Critique 71: 63-86.

Landsberg, Alison. 2004. Prosthetic memory: The transformation of American remembrance in the age of mass culture. New York: Columbia University Press.

Landsberg, Alison. 2009. Memory, Empathy, and the Politics of Identification. International Journal of Politics, Culture, and Society 22(2): 221-229. 
Lazar, Alon, Julia Chaitin, Tamar Gross, and Dan Bar-on. 2004. Jewish Israeli teenagers, national identity, and the lessons of the holocaust. Holocaust and Genocide Studies 18: 188-204.

Lazar, Alon, Tal Litvak-Hirsch, and Julia Chaitin. 2008. Between culture and family: Jewish-Israeli young adults relation to the holocaust as a cultural trauma. Traumatology 14: 93-102.

Litvak-Hirsch, Tal, and Dan Bar-On. 2006. To rebuild life: A longitudinal study of the influences of the holocaust on the following generations. Family Process 45: 465-483.

McCann, Lisa, and Laurie Anne Pearlman. 1990. Vicarious traumatization: A framework for understanding the psychological effects of working with victims. Journal of Traumatics Stress 3: 131-149.

Novick, Peter. 1999. The holocaust and collective memory. London: Clays Ltd.

Prince, Robert. 2009. Psychoanalysis traumatized: The legacy of the holocaust. The American Journal of Psychoanalysis 69: 179-194.

Richmond, Nancy. 1993. Israel's law of return: Analysis of its evolution and present. Application. Dickinson Journal of International Law 12(1): 95-133.

Rocker, Simon. 2014. Survey: Demand for schools has peaked. The Jewish Chronicle Online. Accessed 30 January 2015.

Rosenheck, Robert, and Paul Nathan. 1998. Secondary traumatization in children of Vietnam veterans. Hospital and Community Psychiatry 36: 538-539.

Scharf, Miri. 2007. Long-term effects of trauma: Psychosocial functioning of the second and third generation of holocaust survivors. Development and Psychopathology 19: 603-622.

Schmool, Marlena, and Frances Cohen. 1998. A profile of British Jewry: Patterns and trends at the turn of a century. London: Board of Deputies of British Jews.

Silver, Craig. 2009. Bid to firebomb synagogue as protests grow. London: The Jewish Chronicle.

Tatla, Darshan S. 2006. The morning after: Trauma, memory and the Sikh predicament since 1984. Sikh Formations: Religion, Culture, Theory 2(1): 57-88.

Volkan, Vamik, D. 2001. Transgenerational transmission and chosen traumas: An aspect of large-group identity. Group Analysis 34 (79): 1-20.

Zerubavel, Yael. 1996. Social memories: Steps to a sociology of the past. Qualitative Sociology 19(3): $283-299$.

Christina Fuhr is a Research Fellow at St. Edmund's College, University of Cambridge, and at the Woolf Institute in Cambridge. 